\title{
Tat Responses on Achievement Motivation among Tribal and Non-Tribal College Students of Assam
}

\author{
Manidipa Baruah ${ }^{1}$, Asha Devi $^{2}$ \\ 1,2 (Department of Psychology, Gauhati University, Assam)
}

\begin{abstract}
The population of Assam comprises of various tribes with their varied customs and beliefs. The current research study investigates the motivational pattern viz. achievement motivation and the differentiating cultural elements prevalent among the Tribal and Non - Tribal college students of Assam residing in Guwahati city. The sample consisted of 240 college students (120 tribal and 120 non-tribal) ranging from 18-24 years, 60 males and 60 females for both tribal's and non-tribal's. Attempts were made to include all the prominent tribes of Assam viz. Bodo Kachari, karbi, Miris, Lalung, Dimasa Kachari and Rabhas.. Thematic Apperception Test and a semi structured interview schedule were used to gather information about their family types, parental deprivation, parental relations, settlement pattern and ecology. Mean, Standard Deviation, and t-test were the statistical measures adopted in this $2 \times 2$ factorial design study. In addition to this discriminant analysis has been worked out to strengthen the predictive validity of the obtained data. Results from TAT scores reveal significant difference among the two cultures on achievement motivation. Tribals were found to have low achievement motivation as compared to non-tribal students. Further the study yielded an interesting finding that tribal females are high achievers as compared to males, whereas among non-tribal's males are high achievers. Discriminant analysis results depicts n-achievement as the potent factor which has the highest weight (.811) that resulted in determining the competence and skill of the non-tribal students over the tribal students.
\end{abstract}

Key Words- Culture, discriminant analysis, factorial design, Motivation, n-Achievement, Predictive Validity, Tribal, TAT

\section{Introduction}

Achievement motivation is the desire to accomplish difficult tasks and to meet standards of excellence. This motive implies the desire for success. It is present whenever someone is concerned with attaining some sort of standard, set by himself or others. Parental expectations and cultural influences appear most important in the development of achievement motivation as well as cognitive factors underlying the self-concept which is the way in which a person thinks about herself or himself in a global sense. In its theoretical formulation, Atkinson (1957) and Mc Clelland's (1985) theory of achievement motivation combined n Achievement with cognitive expectations of success and with the value of such success to a person. Growing evidence suggest that countries in which achievement motivation is strong tend to experience more rapid economic growth than countries in which such motivation is relatively weak. The early study of achievement motivation generally owes much in terms of theory and methodology to the work of Mc Clelland and his associates (Atkinson, 1958; Atkinson \& Feather, 1996; Atkinson \& Raynor, 1974). This early work gave impetus to much research into the range of issues to need achievement. According to need achievement theory, achievement behavior is characterized by a psychological need to excel, a desire to enter the competitive race for social status, and a willingness to adopt the high value placed on personal achievement and a success in Western societies. This early Mc Clelland's position held that such achievement motivation was a personality trait that develops in some people more than others as a result of early socialization pressures, in particular independence and mastery training and emotional accomplishments.

Many cross cultural research on motivation has adopted Mc Clelland; need-achievement framework. Mc Clelland defines achievement motivation as a personality disposition to compete with the standard of excellence and he links the motive's development in individuals and cultures to child-rearing practices that stress early self-reliance and a sense of personal mastery over successful task performance. These conceptualizations may be culture bound in its emphasis on individualistic and competitive striving for personal goals and its minimal attention to diverse cultural meanings and modes of achievement.

The state of Assam has made valuable contribution to the cultural, racial and religious heritage of India. The craftsmanship of the people of this region was well known in ancient India. Handicrafts from this region enriched the culture of India as a whole. Especially the art of weaving silk and the unusual cotton hand weaving and exotic pattern have proven its uniqueness from the rest of India. In India tribal development has become a constitutional obligation. The constitution of India directs the state to promote special care. The education and economic interests of the schedule tribes are protected from social injustice and all forms of exploitation. It also provides special financial assistance to states for implementing development scheme. In matters of political 
representations and jobs special reservations has been provided. Now gradual changes are seen in their life, as they are getting opportunity to interact with other advanced social groups. Yet development is slow. What could be the reason for this? Could it be due to lack of motivation? The present study was thus undertaken to see if the tribal's and the non-tribal's differed in there need for achievement. Thus the present study focuses on motivational pattern in terms of need for achievement of tribal's and non-tribal's which are nurtured and shaped in their respective cultural milieu.

\subsection{Hypotheses/Research Questions}

The basic question of research looks at: (a) the difference between n- Achievement among tribal and non-tribal students (b) Gender differences on $n$ - Achievement both within and between cultures i.e. between tribal male VS tribal female, non-tribal male VS non-tribal female, tribal male VS non-tribal female, Non-tribal male VS tribal female.

\subsection{Objectives of the study}

The objectives of this research project are to:

1. To find out the differentiating cultural elements prevalent among tribal's

2. To assess the motivational drive among tribal's viz n-achievement and to find out whether their motivational pattern really differ from the non-tribal college students.

\subsection{Significance of the study}

1. The result of the analysis will be helpful in understanding the motivational pattern of the tribal's and will serve as a useful aid for the Government in implementing development sponsored projects. Further it will facilitate any sort of investigation program for the upliftment of tribal people of Assam.

2. This study may pave the way for the formulation of enriched stimulating environment which will shape the $\mathrm{n}$-achievement of the tribal's in the right direction.

\subsection{Justification of the Study}

The slow progress of our state in coping up with the rest of India in spite of being rich in natural resources as well as culturally has created concern. Could it be the tribal's of Assam who are inevitable part of the Assamese civilizations? Whether motivational problem is a potent cause behind the tribal's retarded development.

\subsection{Limitation of the Study:}

1. The cultural elements prevalent among tribal's who produces significant difference on the level of motivation could not be extensively explored due to time constraints. The cultural elements are required to be studied thoroughly studied so that the correlational relationship with psychological and motivational factors can be established.

2. The researcher cannot study the tribal youths from their inhabiting areas.

\subsection{Delimitation}

The research will therefore be delimited to tribal students of colleges located in guwahati city.

\subsection{Research Design}

\section{Research Methodology}

In the present investigation $2 \mathrm{X} 2$ factorial design has been adopted. Two main independent variables are investigated having two different factors namely:

Culture- Tribal Vs Non-Tribal

Sex- $\quad$ Male Vs Female

\subsection{Sample:}

The sample will include 120 tribal college students and 120 non-tribal students i.e. 240 altogether ranging from 18 to 24 years, out of which 60 students are male and 60 students are female in each group. Tribal college students were from the popular tribes of Assam viz. Bodo Kachari , Karbi, Miris, Lalung, Dimasa kachari, Rabha.

\subsection{Procedure/Method}

Descriptive research involves collecting data in order to test the hypotheses or answer questions concerning the current status of the subject of the study. Descriptive data are typically collected through a 
questionnaire, interview or observation. Thus the current research will adopt a descriptive method undergoing the procedure of (1) Selecting sample of a population, 2) Collecting information through questionnaires, 3) synthesizing findings based on the collected data in order to gauge the motivational pattern of the tribal and the non-tribal students.

\subsection{Data Collection}

\subsubsection{Sampling Technique}

The sampling technique that the researcher will adopt is that of Purposive sampling method as the researcher has some belief that the sample being handpicked is typical of the population.

\subsubsection{Research tools}

This research will be conducted around two major tools of research to assess the achievement motivation of the students and exploring the cultural components. 1) Interview Schedule 2) Thematic Apperception Test.

\subsubsection{The Interview Schedule:}

The interview schedule is one of the important sources of data collection. This schedule included 15 items. The items are taken from the following category:

a) Demographic- It consists of items like age, sex and education.

b) Home environment: It includes items related to home conditions and parental relationship.

c) Cultural Variables: The items related to settlement pattern and ecology are taken as investigating factors All the questions included were close ended.

\subsubsection{Thematic Apperception Test-}

Thematic Apperception Test, also known as TAT is a widely used projective technique used both in clinical as well as non-clinical setting. It was developed by Murray in 1935. According to Murray the purpose of TAT is to reveal " some dominant drives,emotions,sentiments,complexes and conflicts of personality "This. test consists of a series of ambiguous pictures. Persons taking the test are asked to make up stories about them. These are then scored for the presence of achievement -related content according to carefully developed scoring manuals. The result is a score for achievement motivation. However as TAT is administered on the Indian Sample so the Indian Adaptation of this test by Dr Uma Choudhury has been used.

\subsection{Data Analysis of Interview Schedule:}

\section{Result And Discussion}

240 students were given the schedule and the response rate was $100 \%$. The first five questions which were based upon demographic information. It shows that the mean age of the tribal and non-tribal college students are 21.08 and 21.06 respectively. Again with regard to education students from different educational status viz., graduation and post graduation were matched. Number of students in graduation were 20 males and 24 females among both tribal and non-tribal while in post-graduation number of students were again 40 males and 36 females, among tribal's as well as non-tribal's. Again most of the students were from middle class family from both cultures. Therefore it can be inferred with assertion that the subjects were matched on demographic variables viz., age, educational status, family class.

Responses on questions pertaining to family environment are presented below:

\section{TABLE NO 1(a)}

Table 1 (A): Showing Type of Family among tribal and non-tribal college students

\begin{tabular}{|l|l|l|}
\hline TYPE OF FAMILY & TRIBALS $(\mathrm{N}=120)$ & NON-TRIBALS $(\mathrm{N}=120)$ \\
\hline JOINT & 12 & 5 \\
\hline NUCLEAR & 108 & 115 \\
\hline $\begin{array}{l}\text { AVERAGE NUMBER OF FAMILY } \\
\text { MEMBERS }\end{array}$ & 7.61 & 5.87 \\
\hline
\end{tabular}

The data obtained indicates that very few subjects had joint family. In tribal it is $10 \%$ and in non-tribal's it is only $4.15 \%$ as compared to nuclear families in tribal's and non-tribal's being $90 \%$ and $95.85 \%$ respectively. On the other hand the average number of family members of the tribal's are 7.61 which is higher the non-tribal's being 5.87. This indicates commonality in relation to the type of family showing nuclear pattern.

Table 1(B): Showing Parental deprivation

\begin{tabular}{|l|l|l|l|l|}
\hline \multicolumn{4}{|l}{ TRIBALS } & NON-TRIBALS \\
\hline & Dead & Alive & Dead & Alive \\
\hline FATHER & $24(20 \%)$ & $96(80 \%)$ & $14(11.66 \%)$ & $106(88.33 \%)$ \\
\hline MOTHER & $11(9.15 \%)$ & $109(91.85 \%)$ & $6(5 \%)$ & $114(95 \%)$ \\
\hline
\end{tabular}


It has been observed that most of the subjects have both parents alive. Among tribal's $80 \%$ of their father are alive while among non-tribal's $88.33 \%$ are alive . In case of mothers it was seen that among tribal's $91.85 \%$ were alive and again among non-tribal's it was $94 \%$. It appeared that both these groups of students were reared and nurtured by both parents.

Table 1 (C): Showing Parental Relations

\begin{tabular}{|l|l|l|}
\hline PARENTAL RELATION & TRIBALS & NON-TRIBALS \\
\hline Good & $104(86 \%)$ & $106(88.33 \%)$ \\
\hline Bad & $16(13.50 \%)$ & $14(11.66 \%)$ \\
\hline
\end{tabular}

In Assam both tribal's and non-tribal's show good relationship among parents. The percentages of families where healthy relation prevails among parents surpass that of families with strained parental relations for both tribal's as well as non-tribals. The families with good relations for tribal's and non-tribal's are $86 \%$ and $88.33 \%$ respectively. Whereas bad relations were $13.50 \%$ and $11.66 \%$ among tribal's and non-tribal's respectively. The above data thus shows that congenial atmosphere exist in the homes of families among both the cultures.

The last part of the schedule consists of questions relating to settlement pattern and ecology and the responses are shown in the table below:

Table 1 (d): Showing Settlement Pattern

\begin{tabular}{|l|l|l|}
\hline Type of Settlement & Tribal's & Non-Tribal's \\
\hline Permanent Settlement & 111 & 120 \\
\hline Restricted Wondering & 0 & 0 \\
\hline Within Territory & 0 & 0 \\
\hline $\begin{array}{l}\text { Semi Permanent Moving in } \\
\text { village when environment is } \\
\text { exhausted }\end{array}$ & 9 & 0 \\
\hline
\end{tabular}

Although there are a few instances of semi-permanent type of settlement among tribal's, nomadic wondering has become obsolete altogether even their grandparents who live in the hills are out of it.

Table 1(E): Showing Nature of livelihood

\begin{tabular}{|l|l|l|}
\hline TYPE & TRIBAL $(\mathrm{N}=120)$ & NON-TRIBALS $(\mathrm{N}=120)$ \\
\hline Service Dominant & 21 & 61 \\
\hline Agriculture Dominant & 73 & 57 \\
\hline Agriculture and Fishing Dominant & 24 & 2 \\
\hline Agriculture/ Hunting and Gathering & 2 & 0 \\
\hline Hunting \&Gathering Dominant & 0 & 0 \\
\hline
\end{tabular}

It is seen that tribal population is predominantly agricultural with instances of hunting and fishing practiced in some tribes inhabiting in interior areas and forests. There is also shift into secondary and tertiary sector with nominal shift

\subsection{Analysis of TAT responses}

The Thematic Apperception Test (TAT) has proved to be very effective tool in researching achievement. The scoring methodology (Murray) with some modification is utilized .Qualitative experiences of the stories are also included at the time of scoring.

Table 2: Showing Mean and Standard Deviation for the scores obtained on TAT for nAchievement for tribal and non-tribal college students

\begin{tabular}{|l|l|l|}
\hline & Mean & Standard Deviation \\
\hline Total tribal students & 9.03 & 3.69 \\
\hline Total non-tribal students & 17.58 & 7.04 \\
\hline Tribal male & 8.35 & 2.80 \\
\hline Tribal female & 9.72 & 4.32 \\
\hline Non-Tribal male & 18.92 & 8.05 \\
\hline Non-Tribal female & 16.25 & 5.63 \\
\hline
\end{tabular}


Table 3: $t$ values for tribal and non-tribal students on $n$-achievement

\begin{tabular}{|l|l|}
\hline & t-values \\
\hline Total tribal's Vs Non-tribal's & $11.78^{* *}$ \\
\hline Tribal Male Vs tribal female & $2.06^{* *}$ \\
\hline Non-tribal male Vs Non-tribal female & $2.10^{* *}$ \\
\hline Tribal male Vs non-Tribal male & $9.61^{* *}$ \\
\hline Tribal Female Vs non-tribal female & $7.31^{* *}$ \\
\hline
\end{tabular}

*significant at 0.01 and 0.05 level of significance

The $\mathrm{M}$ and SD scores indicate scores among tribal and non-tribal college students on $\mathrm{n}$-achievement are 9.03(3.69) and 17.58 (7.04) respectively. The t-value which is 11.78 is found to be significant at both .01 and.05 level. Thus it can be asserted that tribal's are low in achievement motivation as compared to the nontribal.

To study the variation among both the sexes viz-male and female different groups were compared. The $\mathrm{M}$ and SD among tribal male and female is 8.35(2.80) and 9.72(4.32). The value obtained on t test (2.06) is also found to be significant at .05 level. On the other hand the scores obtained on M and SD among non-tribal male and female are 18.92 (8.05) vs. 16.25 (5.63). Here again the value of t-test is also found to be (2.10) which is significant at .05 level. Thus it is interesting to note that among tribal the females are high achievers as compared to males. Comparisons were also made between tribal male Vs non-tribal male and Tribal female Vs non-tribal female with t-value 9.61 and 7.31 respectively which showed a significant difference.

The discriminant analysis has further been worked out to strengthen the predictive validity of the obtained data. The values of Discriminant functions are presented below:

Table 4: Discriminant Functions

\begin{tabular}{|l|l|}
\hline Variables & Functions \\
\hline N-Achievement & .811 \\
\hline N-Power & .212 \\
\hline Affiliation & .235 \\
\hline Aggression & .001 \\
\hline Nurturance & .107 \\
\hline Sex & .287 \\
\hline
\end{tabular}

\subsection{Discussion:}

The findings of the study have shown that there is not much difference among tribal's and non-tribal's in terms of family environment, settlement pattern and nature of livelihood. But insipite of these tribal's were found to be low in n-achievement as compared to the non-tribal's. Related literature supports the findings of Ojha Hardeo (1995) in which Santhal tribal's scored low on n-achievement in comparison to non-tribal. Earlier Gokulnathan and P. Mehta (1972) reported high levels of n-achievement among non-tribal's. The reason could be that the tribal's are less intrinsically motivated because of the special preference by the government they are not required to harness more effort as compared to non-tribal's.

In relation to gender the study yielded an interesting finding that among tribal's the females are higher achievers whereas among non-tribal's results are vice versa. This reflects the tribal cultural tradition where female play an active role in maintaining the family. The obtained results confirm the findings of Mc Clelland et al (1953) on gender differences. He was the first to notice the failure of the need achievement construct to account for achievement in women. Men has been judged as more assertive and competitive, women more relational or affiliative, in their achievement modes.( Broverman, Vogel, Clarkson \& Rosenkrantz, 1972). The Philippines seems to be good choice for cross-cultural comparison of gender differences in achievement motives. Despite the persistent stereotypes of Filipino women as demure and submissive, they generally perform better in school than men, attended college in larger number, and are well represented in high-level positions in some professions. The question raised was whether there is gender difference in academic motives and whether these differences generalized across culture. An affirmative answer to the first question would suggest differential gender socialization for achievement, and to the second question, that these socialization differences are consistent across cultures. However our findings also contradict with studies carried out by Singh (1981) where he found no difference between forward casts and backward caste students on achievement motivation. Again the trend of results on tribal male and female is contrary to the findings of Tandon (1981) who reported that Indian female are low achievers in comparison to male. Results of another study designed by Sandra Graham (1994) to find out the real difference of caste on achievement motivation indicated that there is little reliable evidence to suggest that African Americans and White differs in their underlying need for achievement. 
Discriminant functions are a phase of analysis which examines the functions to determine the relative variable in discriminating between the groups of tribal's and non-tribal's. Here, for the interpretation purposes the ranking of dependent measures are made in terms of relative discriminative power. The discriminant functions involve examining the signs and magnitude of the standardized discriminant weight (sometimes referred to as discriminant co-efficient). The obtained results indicated that the $\mathrm{n}$-achievement has the highest discriminant weight (.811) (Table 4). Thus it can be inferred that n-achievement is the dependent measure which has the most discriminating power between these two cultures namely tribal and non-tribal's.

\subsection{Suggestions:}

A model has been presented to be implemented among tribal youths (college students).

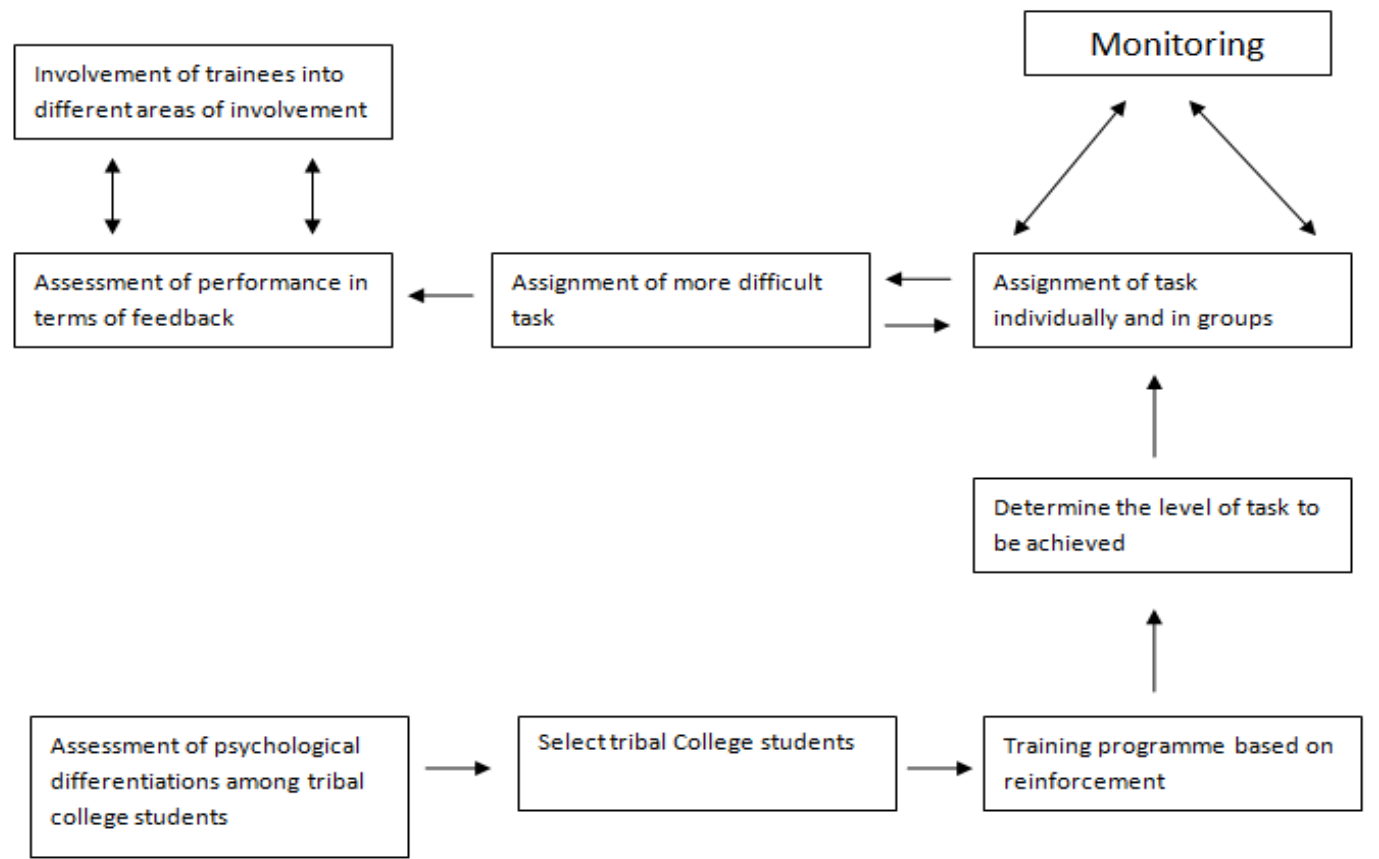

Model: For enhancing the N-Achievement among tribal College students : Psychological differentiations, viz, Intelligence, Perceptual ability.

An attempt has been made to explore the ways in which the level of motivation viz, n-achievement among college students can be enhanced. The tribal college students from different areas of Assam need to be assessed to see psychological differentiations like intelligence and perceptual skill. The tribal college students possessing optimum level of skill and ability are to be selected training but selection should be such that they can represent the entire community. These selected students are provided with reinforcement based training , where the emphasis is made on developing competitive skills and ability to excel for standards. Gradually these trainees acquire knowledge and than they are assigned certain task to compete either individually or in group. The assessment is made on their performance in the form of feedback. After receiving a few months training (at least 6 months), these tribal college students can be engaged in different sponsored schemes to make it more effective. This kind of training will necessarily lead in developing high motivation among tribal youths, which may help them to cope up with the new competitive world in future.

\section{Conclusion}

This research provides a critical first step towards assessing achievement motivation of the college students by using projective technique i.e. Thematic Apperception Test. Attempts were made to include all the popular tribes of Assam. Results indicated that tribal students scored low on n-achievement in comparison to the non-tribal students and therefore they are not able to cope up with the standards of the existing society. In terms of sex difference tribal females were higher achievers than the tribal males whereas among non-tribal's it the male who are higher achievers. This result reflects tribal cultural traditions, where females play an active role in maintaining the family. However this study is not free from limitations as the cultural elements prevalent among tribal's could not be explored which would contribute to produce significant difference on the level of motivation. The sample size of the tribal's were only limited to students residing in Guwahati city, due to time constrains the researcher could not go and study the tribal's in their inhabiting areas. Despite the limitations the 
study however paves the way for encouragement of some research projects which would help the tribal's to develop skills for meeting various life challenges and coping up with the national standards.

\section{References:}

[1] Basow.S.A (1984) Ethnic group differences in educational achievement in Fizi, Journal of Cross-cultural Psychology, 15, 435-451

[2] Biaggio, A.M.B. (1978). Achievement motivation of Brazilian students. International Journal of Intercultural Relations, $2.186-195$

[3] Bulato, J.C. (1962). Hiya. Phillippine studies: 12, 424-438

[4] Coladarci, T. (1993). High school dropout among Native Americans. Journal of American Indian Education, 23, 15-22

[5] McClelland, D.C., Atkinson, J.W., Clark, R.A..,\&Lowell,E.L.(1953). The achievement motive. New York: Appleton-CenturyCrofts.

[6] Mc Shane, D. (1983). Explaining achievement patterns of Americans Indian children: A transcultural and developmental model. Journal of Education, 61, 34-47

[7] Spence, J.T. \&Helmreich, R.L.(1983). Achievement-related motives and behaviours. San Francisco: Freeman

[8] Sinha, Geeta. Exposure to industrial and urban environment, and education and cognitive style among Santhal children. Journal of Personality and Clinical Studies, 6(1), 1990, 113-117.

[9] Schmalt H.D. (1997) Convergent and discriminent validity of various process, 1977 Vol.21 (3), $112-117$.

[10] Singh's. (1997). Achievement motivation and economic growth. Indian Psychological Review of Psychology, 37,523-564

[11] Traindis, H.C et al.(1998). The analysis of subjective culture. Newyork Wiley. 